\title{
Cervical cage without plating in management of type II / II A Hangman's fracture combined with intervertebral disc injury
}

Fuxin Wei ${ }^{1 \dagger}$, Le Wang ${ }^{1 \dagger}$, Zhiyu Zhou ${ }^{1,2+}$, Rui Zhong ${ }^{1}$, Shaoyu Liu ${ }^{1 *}$, Shangbin Cui ${ }^{1}$, Ximin Pan ${ }^{3}$ and Manman Gao ${ }^{1}$

\begin{abstract}
Background: Surgical intervention is increasingly performed as the primary treatment of unstable Hangman's fracture. Some authors have advocated using anterior C2/3 discectomy with interbody fusion and plating to treat unstable Hangman's fracture combined with intervertebral disc injury; however, there are few reports on unstable Hangman's fracture treated by anterior interbody fusion with the cervical cage (PEEK material) solely.

Methods: This study was to assess the efficacy of the cervical cage in management of unstable Hangman's fracture combined with intervertebral disc injury. A cohort of 15 patients with unstable Hangman's fractures fulfilling the inclusion criteria were prospectively submitted to surgical treatment of anterior C2/3 discectomy and interbody fusion using the cervical cage without plating. According to the Levine and Edwards classification, there were 5 type II, and 10 type IIA cases. The clinical outcome (the visual analog scale and the clinical post-traumatic neck score), radiological findings (angulation, translation, and disc height), and bone healing were assessed at 3, 6, 12, and 24 months.
\end{abstract}

Results: All the patients were followed up successfully. There were no intra- or postoperative complications observed. Solid fusion was achieved in all cases by 6 months after surgery. The local kyphotic angle was corrected significantly with the mean preoperative $12.31 \pm 2.96$ degrees, initial postoperative $-1.98 \pm 1.62$ degrees and the latest follow-up $-1.72 \pm 1.60$ degrees respectively $(P<0.05)$. The translation was also corrected significantly with the mean preoperative $3.20 \pm 1.16 \mathrm{~mm}$, initial postoperative $0.97 \pm 0.36 \mathrm{~mm}$, and the latest follow-up $1.05 \pm 0.34 \mathrm{~mm}$ respectively $(P<0.05)$. The mean visual analog scale and the clinical post-traumatic neck score improved significantly following surgery $(P<0.05)$.

Conclusions: This case series demonstrates that anterior $C 2 / 3$ discectomy and interbody fusion with the cervical cage solely is effective and reliable in management of type II / IIA Hangman's fracture with C2/3 disc injury when properly indicated.

\section{Background}

Hangman's fracture, or traumatic spondylolisthesis, which accounts for 4-7 \% of all cervical fractures/dislocations [1], is the second most common fracture of the second cervical vertebra [2]. It involves a bilateral arch fracture of $\mathrm{C} 2$ with a variable degree of displacement of $\mathrm{C} 2$ corpus on $\mathrm{C} 3$ vertebrae. Opinions vary regarding the optimal treatment of Hangman's fracture. Although most Hangman's

\footnotetext{
* Correspondence: gzsyliu@tom.com

†Equal contributors

'Department of Spine Surgery, The First Affiliated Hospital of Sun Yat-sen University, Guangzhou, China

Full list of author information is available at the end of the article
}

fractures are managed conservatively [3, 4], the optimal strategy remains controversial, especially for the type II and II A injuries (according to the classification of Levine and Edwards [5]) which are thought to be unstable.

Most authors recommended that surgical intervention should be reserved for cases with failure of conservative measures; however, pseudoarthrosis, anterior dislocation, angulation of $\mathrm{C} 2$ over $\mathrm{C} 3$, recurrent axial pain were observed in about $60 \%$ of the cases of type II / II A injuries that were primarily treated with conservative therapy, suggesting the need for an early operation in patients with unstable Hangman's fractures [3, 6-8]. In addition, conservative treatment has several disadvantages, such 
as prolonged immobilization with cervical tong traction and/or the halo device for an average of 3-6 months with an uncertain outcome. In particular, in elderly patients, prolonged immobilization might be intolerable. Therefore, the authors preferred early surgical treatment of unstable Hangman's fracture.

Both anterior and posterior approaches can be used to treat lesions at $\mathrm{C} 2$; however, the optimum surgical treatment is controversial [9]. The posterior approach, by which we can avoid major visceral and vascular structures, was preferred for its simple exposure, however, inserting transpedicular screws poses the risk of intraoperative neurological and vascular injuries, which was reported from $11-66 \%$ of injury rate in its early application [10-12]. The anterior approach, which has the advantage of technical ease and a relatively short fusion, is characterized by C2-3 discectomy and interbody fusion with plating [13]. Some authors have reported good clinical results of this approach in management of Hangman's fractures, especially for the patients with $\mathrm{C} 2 / 3$ intervertebral disc injury, however, there are few reports on unstable Hangman's fracture treated by anterior discectomy and interbody fusion (ACDF) using cervical cage without plating, which could shorten the duration of surgery and medical cost, especially for those combined with $\mathrm{C} 2 / 3$ disc injury and disease of vertebral body, such as bone cyst, which could not be inserted screws with plating.

Is anterior C2-3 discectomy and interbody fusion with the cervical cage solely effective and reliable in management of unstable Hangman's fracture combined with $\mathrm{C} 2 / 3$ intervertebral disc injury? To answer the question, we designed this prospective study to assess the clinical and radiologic outcomes of this innovative technique.

\section{Methods}

This study was approved by the institutional review board of the first affiliated hospital of Sun Yat-sen University. Written informed consent had been provided by the subjects (or their representatives) involved in this study. From December 2009 to March 2013, 15 patients with Hangman's fractures were included in this study. The inclusion criterion required the following: type II, IIA (according to the classification of Levine and Edwards [5]) fracture combined with $\mathrm{C} 2 / 3$ disc injury with or without neurologic impairment and age of 20-60 years (nonpathologic adult). Patients with unstable vital signs, severe internal disease or skull fractures, pathological fractures, or cervical vertebral body fractures were excluded.

This study included 10 males and 5 females with an average age of 36.8 years (range, 26-58 years) at the time of operation. Clinical information was shown in Table 1. Referring to the Levine-Edwards classification, 10 patients $(66.7 \%)$ were in type IIA and 5 patients
(33.3\%) were in type II. Axial pain and restricted motion of the spine were complained from all patients immediately after injury. According to the American Spinal Injury Association scale [14], 2 cases were graded as spinal injury $C, 4$ cases were $D$, and grade $E$ for other cases.

Skull traction was performed for all the cases preoperatively. According to the type of the individual case, a weight of 3-5 kilogram with an appropriate angle was applied to stabilize and reduce the fracture. At least $50 \%$ degree of reducing was accomplished in all the cases without advanced neurological deficits or deterioration. All patients performed neck extension exercises under constant traction without neurologic deterioration.

Anterior $\mathrm{C} 2 / 3$ cervical discectomy and autologous bone fusion with a polyetherether ketone (PEEK) cage (Solis, Stryker Corporation, Cestas, France) was performed in each patient by the same senior author. The patient was placed in the supine position with the neck slightly extended and 3-5 $\mathrm{kg}$ of axial traction. After anesthesia, fiberoptic bronchoscope-guided nasal intubation was performed. The head of the patient was taped and turned away from side of incision. Surgical procedure was performed using a standard anterior SmithRobonson approach. A longitudinal incision was made from the angle of the jaw to the hyoid bone. After $\mathrm{C} 2 / 3$ anterior exposure was obtained, all the patients were found to have a partial tear of the anterior longitudinal ligaments and disc disruption. To facilitate decompression, stable placement of self-retaining retractors were used in operation. Retraction on the cephalad of the incision was best accomplished by bending a malleable retractor, which could be used as a lever against the vertebral body of $\mathrm{C} 2$. After elevating the soft tissues cephalad and superiorly, we got enough exposure to access the disc level and to place instruments. It was helpful to avoid injury of the esophagus and sympathetic chain by careful placement of retractors. Microscopeassisted discectomy and decompression were performed followed by removing the skull traction after distracting the disc space using the casper system under fluoroscopic guidance. The endplates were curetted to remove cartilage and the bony endplates were preserved. Under continuous imaging control, the fracture reduction was reduced as much as possible by placing the head in a more slightly extended position and pushing the vertebral body of $\mathrm{C} 2$ backward gently to close the remaining gap. After that, the iliac-crest bone graft was harvested. We used a specialized hollow cylindrical gouge that accompanied the Solis instrumentation set to core a critical amount of cancellous bone out from the iliac crest between the inner and outer tables. Intraoperative sizing was performed for the cage using the templates under fluoroscopic guidance. The cage was filled with comminuted bone graft and tightly impacted into the prepared 
Table 1 Summary of the Data of 15 Patients in This Study

\begin{tabular}{|c|c|c|c|c|c|c|}
\hline Case & Age/gender & Injury & Diagnosis & ASIA & Hosp.stay (days) & Results \\
\hline 1 & $30 / F$ & VA & $\|+\mathrm{STI}+$ fracture of right radius & $\mathrm{C}$ & 12 & Union \\
\hline 2 & $30 / \mathrm{M}$ & VA & $\| A+S T I$ & $\mathrm{E}$ & 7 & Union \\
\hline 3 & $38 / \mathrm{M}$ & VA & $\| \mathrm{A}$ & $\mathrm{D}$ & 6 & Union \\
\hline 4 & $25 / F$ & VA & $\| \mathrm{A}+\mathrm{STI}$ & $E$ & 7 & Union \\
\hline 5 & $35 / \mathrm{M}$ & Others & $\|\mathrm{A}+\mathrm{H}\|$ & $\mathrm{D}$ & 9 & Union \\
\hline 6 & $40 / \mathrm{M}$ & VA & $\| A+S T I$ & $\mathrm{E}$ & 7 & Union \\
\hline 7 & $45 / F$ & VA & $\|+\mathrm{STI}$ & $\mathrm{E}$ & 5 & Union \\
\hline 8 & $59 / F$ & Falling & $\| \mathrm{A}+\mathrm{HI}+\mathrm{STI}$ & $\mathrm{D}$ & 7 & Union \\
\hline 9 & $30 / \mathrm{M}$ & VA & $\|+$ fracture of left humerus & $\mathrm{D}$ & 7 & Union \\
\hline 10 & $40 / \mathrm{M}$ & Others & $\| \mathrm{A}+\mathrm{H}$ & $\mathrm{E}$ & 6 & Union \\
\hline 11 & $26 / F$ & VA & $\|+S T I$ & $\mathrm{E}$ & 5 & Union \\
\hline 12 & $28 / \mathrm{M}$ & VA & $\| \mathrm{A}+\mathrm{HI}+\mathrm{STI}$ & $E$ & 6 & Union \\
\hline 13 & $58 / \mathrm{M}$ & Falling & $\|+$ fracture of right raidus & E & 7 & Union \\
\hline 14 & $32 / \mathrm{M}$ & VA & $\| \mathrm{A}+\mathrm{STI}$ & C & 14 & Union \\
\hline 15 & 29/M & VA & $\| A+S T I$ & $E$ & 5 & Union \\
\hline
\end{tabular}

VA indicates vehicle accident, STI soft tissue injury; $H I$ head injury; Others, hit by a heavy falling objects, ASIA American Spinal Injury Association, FU follow-up

disc space. Finally, the reduction and proper position of the cage was ascertained again under imaging control.

Closure of the wound was performed in layers with the routine use of a suction drain which was removed within 24 hours. All patients had prophylactic antibiotic coverage for 24 hours. Postoperative immobilization was accomplished with a hard cervical collar for 6-10 weeks.

Patients were followed up at 3, 6, 12 and 24 months after operation. Clinical and radiological outcomes were assessed respectively. Clinical assessment was performed by an independent examiner at each visit, using the visual analog scale (VAS) form for neck pain and the clinical post-traumatic neck score (PTNC) [15] which contains critical information such as cervical movement, neurological statue and daily leaving activities. Radiological assessment involved plain x-ray film assessment of local kyphotic angle of $\mathrm{C} 2 / 3$, the anterior translation of $\mathrm{C} 2$ pre and postoperatively, and the postoperative disc height changes of C2-3. The local kyphotic angle was defined as the angle formed by lines drawn along the inferior endplate of axis and the inferior endplate of C3 (Fig. 1) [16]. Translation was measured as the distance between parallel lines drawn through the posterior border of C3 and the inferior endplate of C2 (Fig. 1) [17]. The disc height was the mean of the sum of the vertical distance between the anterior and posterior edges of the vertebral end plates. [17]

At 3 and 6-month follow-up, dynamic lateral flexion/ extension radiographs and additional $\mathrm{CT}$ scans were also performed for all the patients to ascertain the fusion status. The criteria of fusion were as follows [18]: (1) trabecular bone across the interfaces and connects superior and inferior vertebral bodies; (2) radiolucency inside the cage disappeared; (3) Adequate disc height was restored, without collapse-induced kyphosis; (4) the flexion-extension range of motion at the fusion site was $2^{\circ}$ or less.

All the images were reviewed by the same radiologist and assessor who were blinded to the clinical outcome of the patients. Measurements were done on digital radiographs with in-built software to measure distance and angle up to the accuracy of $0.01 \mathrm{~mm}$ and $0.1 \mathrm{de}$ gree respectively (Philips DICOM Viewer R2.5, Philips Medical Systems Nederland B.V., Best, The Netherlands).

The SPSS (version16.0, Chicago, IL, USA) package was used for the statistical analysis. The data of the ASIA scale, VAS, PTNC score and local kyphotic angle were analyzed using the Wilcoxon signed ranks test, with a confidence interval of $95 \%$. The data of translation were analyzed using One-way Analysis of Variance. The data of disc height between initial postoperative and the latest follow-up was compared by using paired $t$ test. Data were presented as the mean \pm standard deviation. Statistical significance was indicated at $P<0.05$.

\section{Results}

The average total operative time was 93.5 minutes (range 82-130 minutes) with blood loss was $23.3 \mathrm{cc}$ (range $20-50 \mathrm{cc}$ ). The average hospital stay was 7.3 days (range4-15 days). All the patients were followed up successfully. Fusion was evident at 3-6 months postoperatively in all cases (Figs. 2 and 3).

A summary of clinical outcomes was provided in Table 2. Of the total 15 patients, there was a significant 


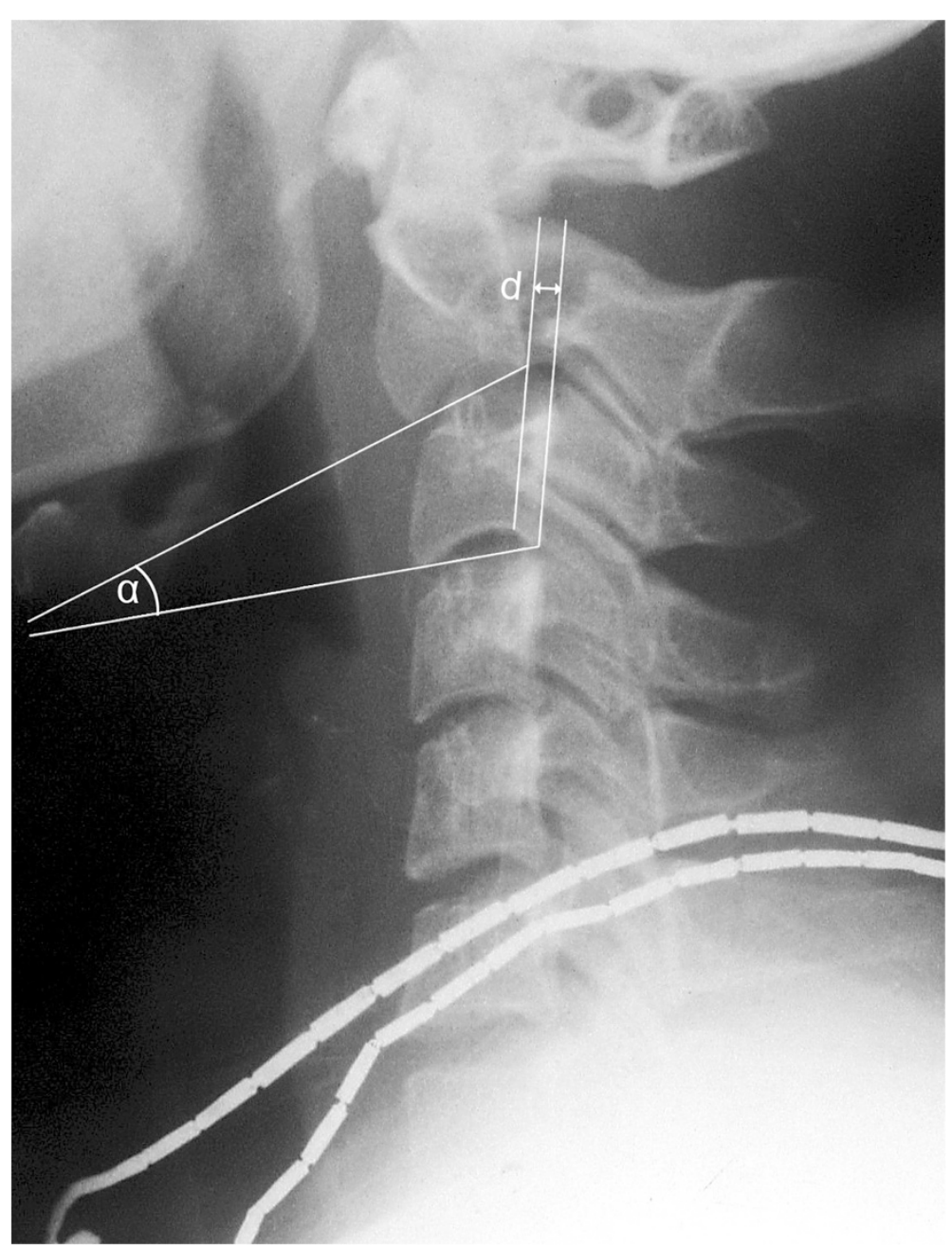

Fig. 1 Diagram showing the local kyphotic angle and translation. $a$ is the angle between inferior border of C2 and s C3. $d$ is the distance between posterior boarders of C2 and C3

improvement between preoperative VAS and either 3month follow up or 24-month follow-up VAS score $(\mathrm{z}=-3.431, P<0.01 ; \mathrm{z}=-3.436, P<0.01$, respectively, Table 3). Significant improvement was also achieved between preoperative PTNC and either 3-month follow-up or the 24-month follow-up PTNC $(\mathrm{z}=-3.409, P<$ $0.01 ; \mathrm{z}=-3.414, P<0.01$, respectively, Table 3 ).

Neurological status improved from $C$ and $D$ to $E$ in all 6 cases. No patient experienced worsening neurological function postoperatively. There was significant postoperative neurologic improvement compared with patients' preoperative neurologic function $(\mathrm{z}=-2.136, P=0.003)$.

A summary of radiological outcomes is provided in Table 4. The preoperative and initial postoperative local kyphotic mean angle was $12.31 \pm 1.8^{\circ}$ and $-1.98 \pm 1.62^{\circ}$ respectively, which differed significantly $(P<0.01$, Table 3). The mean translation of $\mathrm{C} 2$ also improved significantly after surgery $(\mathrm{z}=-3.408, P<0.01$, Table 3$)$. There were no significant correction loss of radiological results at the final follow up $(\mathrm{z}=-1.710, \mathrm{P}>0.05$, Table 3). The initial postoperative and the latest follow-up mean $\mathrm{C} 2-3$ disc height was $7.10 \pm 0.74 \mathrm{~mm}$ and $7.07 \pm 0.73 \mathrm{~mm}$ respectively, which did not differ significantly $(\mathrm{t}=1.970, P=0.069)$.

The complications observed included minor implant migration of one patient at 1 week postoperatively without any symptom complained. Cervical orthosis was administrated to limit movement after being discharged. The X-ray showed the implant remained the same position during follow-up. Bone fusion was confirmed using CT scan at 4 months postoperatively (Fig. 4). One case suffered superficial infection, which was cured 2 weeks after medication.

\section{Discussion}

Various surgical or nonsurgical treatments of Hangman's fracture have been described, but the optimal treatment remains in question [3, 4, 19]. Although nonsurgical 

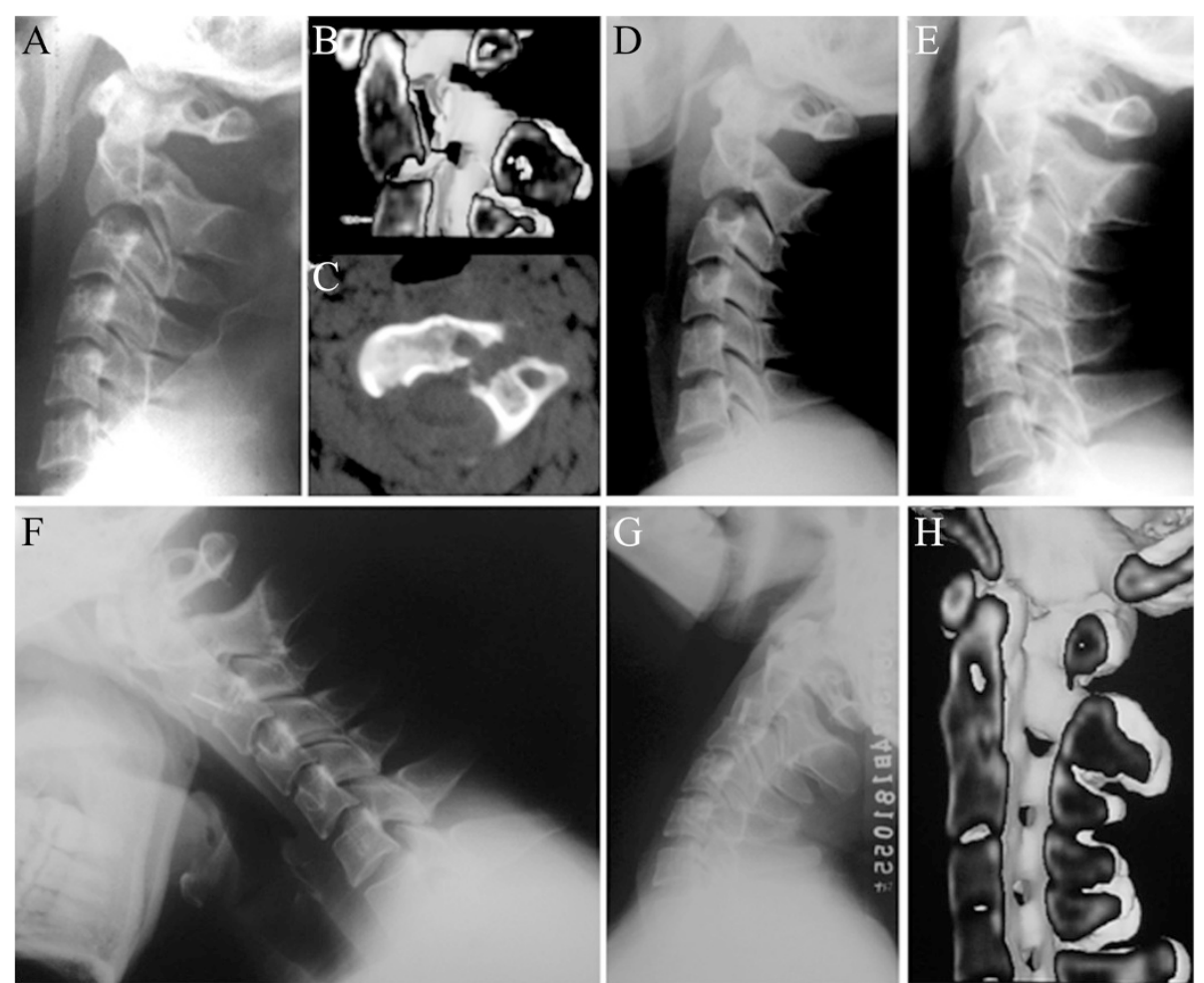

Fig. 2 Images of a 38-year-old male patient. a and $\mathbf{b}$, preoperative lateral X-ray and CT scans showing a type IIA hangman's fracture with severe angulation. c, CT with axial section showing a bone cyst in the vertebral body of C2. $\mathbf{d}$, Some degree of reducing was accomplished during skull traction for 3 days. e, 3-month postoperative lateral X-ray showing adequate reduction and bony fusion. $\mathbf{f}$ and $\mathbf{g}$, 24-month flexion/extension lateral X-rays showing no range of motion at the fusion site. $\mathbf{h}$, CT with sagittal reconstruction showing solid fusion and fracture healing

treatments were widely favored in the primary management of a Hangman's fracture, healing was slow and uncertain, and the course of treatment for the fracture was long. Studies have shown that anterior dislocation, angulation of $\mathrm{C} 2$ over $\mathrm{C} 3$, pseudarthrosis, and recurrent axial pain occurred in about $60 \%$ of patients with type II, IIA and III fractures after conservative treatment $[3,5,19]$. It was reported that the union rates following conservative management in type II, IIA and III fractures were $60,45,35 \%$ respectively [9]. Some authors insisted that nonsurgical management was inappropriate in patients with unstable Hangman's fractures and discoligamentous injuries, due to the absence of a blood supply to the disc, which is unable to repair itself. [20] This frustrating fact could explain why many surgeons choose primary operation in management of unstable Hangman's fracture [8, 21-23], which could shorten the course of treatment [24]. Another reason for operation is that surgical intervention is employed in the hope of improving neurological outcome [5] or for patients suffering persistent pain from the cervical spine after treated with an external orthosis.

Surgical stabilization has been accomplished in both anterior and posterior approaches. Due to the complex anatomic feature of the upper cervical spine, the posterior approach was preferred for its relative simple exposure with no major vascular or visceral structure. Among the different posterior approaches, direct posterior fixation of the pedicles or pars fracture with a screw across the fracture line was reported with the advantage of motion reservation in $\mathrm{C} 2-\mathrm{C} 3[7,21,25]$. However, it had been reported that it was ineffective in patients with unstable fractures due to discoligamentous injury in C2-C3, failing of preventing kyphosis and loss of disc height. [26] Redislocations in discoligamentous unstable Hangman's fracture following direct pars repair have also been reported $[4,26]$. Although pedicle screw fixation has been reported with good clinical outcomes, it posed the risks of intraoperative neurological and vascular injuries [10-12]. Yukawa et al. [27] reported the perforation rate of pedicle screws in $\mathrm{C} 2$ and C3 was $21.6 \%$. Although a computer-guided surgical navigation system has been carried out to improve the accuracy of screw insertion [8], these systems were not installed in most hospitals owing to their high cost and user unfriendliness. Another shortcoming of posterior approach was the axial pain after operation.

In this instance, we advocated an anterior $\mathrm{C} 2-3$ discectomy and fusion (ACDF) for unstable hangman's fracture, which has been confirmed to be an effective 

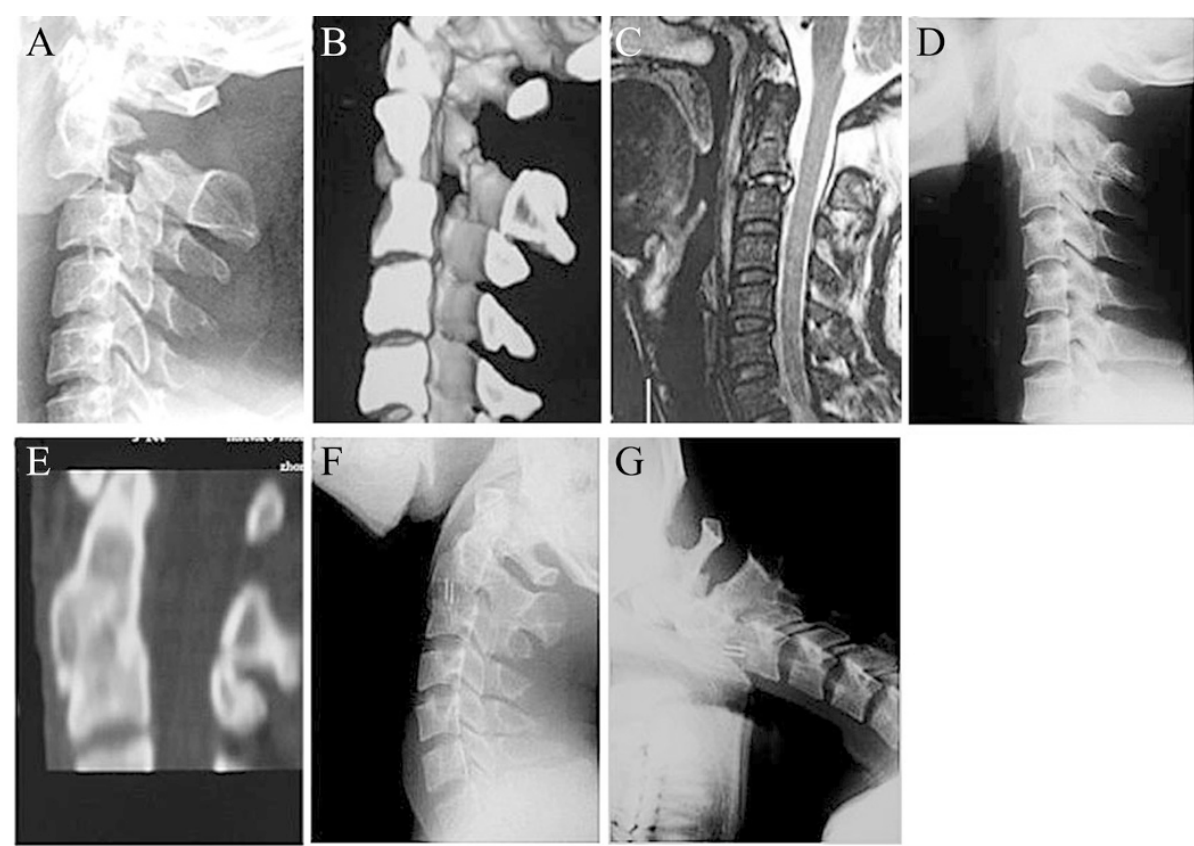

Fig. 3 Images of a 40-year-old male patient. $\mathbf{a}$ and $\mathbf{b}$, preoperative lateral X-ray and CT scans showing a type II Hangman's fracture with severe translation. c, MRI with sagittal section showing C2/3 intervertebral disc injury. $\mathbf{d}$, 3-month postoperative lateral X-ray showing adequate reduction and bony fusion. e, CT with sagittal reconstruction showing solid fusion and fracture healing. $\mathbf{f}$ and $\mathbf{g}$, 24-month flexion/extension lateral X-rays showing no range of motion at the fusion site

strategy [3, 23, 28]. Although a high anterior exposure was once considered to be complex and might impose a risk to vital structures, all the incisions were exposed without difficulty and there were no intraoperative complications reported in this study. In our series, the standard anterior Smith-Robonson approach was used, which was same as what Tuite et al. described in 1992 [6]. According to our experience in the 15 cases, anterior approach offered satisfied exposure for reduction and arthrodesis. Pre and intraoperative axial traction with

Table 2 Summary of VAS and PTNC scores

\begin{tabular}{|c|c|c|c|c|c|c|}
\hline \multirow[b]{2}{*}{ Case No. } & \multicolumn{3}{|c|}{ VAS Score } & \multicolumn{3}{|c|}{ PTNC Score } \\
\hline & Preop & 3-month FU & 12-month FU & Preop & 3-month FU & 12-month FU \\
\hline 1 & 9 & 2 & 1 & 28 & 76 & 95 \\
\hline 2 & 5 & 0 & 0 & 53 & 78 & 95 \\
\hline 3 & 7 & 0 & 0 & 35 & 81 & 98 \\
\hline 4 & 6 & 1 & 0 & 55 & 68 & 96 \\
\hline 5 & 7 & 1 & 0 & 53 & 79 & 98 \\
\hline 6 & 8 & 3 & 1 & 21 & 58 & 93 \\
\hline 7 & 6 & 0 & 0 & 35 & 81 & 96 \\
\hline 8 & 8 & 1 & 1 & 31 & 76 & 93 \\
\hline 9 & 8 & 1 & 0 & 35 & 73 & 98 \\
\hline 10 & 5 & 1 & 0 & 56 & 68 & 95 \\
\hline 11 & 7 & 1 & 0 & 51 & 76 & 93 \\
\hline 12 & 3 & 0 & 0 & 59 & 78 & 100 \\
\hline 13 & 8 & 2 & 2 & 41 & 73 & 93 \\
\hline 14 & 4 & 2 & 0 & 58 & 76 & 100 \\
\hline 15 & 7 & 1 & 0 & 35 & 68 & 98 \\
\hline
\end{tabular}

VAS indicates visual analog scale; PTNC, post-traumatic neck score; FU, follow up 
Table 3 Clinical and Radiological Outcomes Pre and Postoperatively

\begin{tabular}{lllll}
\hline & VAS & PTNC & Local Kyphotic Angle $\left(^{\circ}\right)$ & Translation (mm) \\
\hline Preoperative & $6.5 \pm 1.7$ & $43.1 \pm 12.5$ & $12.31 \pm 2.96$ & $3.20 \pm 1.16$ \\
Postoperative & $1.1 \pm 0.9$ & $73.9 \pm 6.2$ & $-1.98 \pm 1.62$ & $0.97 \pm 0.36$ \\
Follow up & $0.3 \pm 0.6$ & $96.1 \pm 2.5$ & $-1.72 \pm 1.60$ & $1.05 \pm 0.34$ \\
$P^{*}$ & 0.006 & 0.004 & 0.001 & 0.001 \\
$P^{* *}$ & 0.010 & 0.033 & 0.681 & 0.131 \\
\hline
\end{tabular}

All values are shown as average \pm standard deviation

VAS indicates visual analog scale, PTNC post-traumatic neck score

$P^{*}$ : Postoperative VS Preoperative

$P^{* *}$ : Follow up VS Postoperative

slightly neck extension of the patients combined with the head turning away from side of incision facilitate the exposure. In extension, the mandible was more cephalic, which could save more space for the cephalic movement of the retractor, then facilitate the stretching range of exposure.

Many of the ACDF-associated complications were graft-related problems. [29, 30] Cervical anterior plate systems were introduced in response to some of these problems; however, plate-assisted fusion has itself been associated with plate fracture, screw back-out and fracture, and soft-tissue injury to structures such as the esophagus [31, 32]. Although the utilization of anterior cervical plates helps to shorten the duration of postoperative immobilization, it increases the duration of surgery and is associated with problems of soft-tissue injury as well as instrumentation failure [33]. In particular, anterior cervical plating is inappropriate for patients with poor bone quality of cervical vertebral body, such as bone cyst, which could not provide sufficient pullout strength at the screw-bone interface. Interestingly, Savolainen et al. prospectively compared the fusion rate of autologous bone graft with or without plus plating on anterior operations for cervical spondylosis. Of these, both of the two groups achieved $100 \%$ fusion rate [34].

In this study, with the advent of minimal invasive surgery, we utilized the cervical cage (PEEK material) without plating for C2-3 discectomy and fusion (ACDF) in management of type II / IIA Hangman's fractures, which required a less invasive approach and showed good clinical and radiological results at the latest follow-up (Figs. 2 and 3). A concern arises that it might not provide adequate stability for the Hangman's fracture. The configuration of the superior and inferior surfaces of the cage conforms to the shape of the respective opposing surface of the disc space, and it has retention teeth as well as bilateral titanium spikes on the superior and inferior surfaces, which could provide a secure

Table 4 Summary of Radiological Measurements Pre and Postoperatively

\begin{tabular}{|c|c|c|c|c|c|c|}
\hline \multirow[b]{2}{*}{ Case No. } & \multicolumn{3}{|c|}{ Local kyphotic angle $\left(^{\circ}\right)$} & \multicolumn{3}{|c|}{ Translation (mm) } \\
\hline & Preop & Initial Postop & The Latest FU & Preop & Initial Postop & The Latest FU \\
\hline 1 & 13.2 & -1.8 & -1.3 & 4.88 & 1.23 & 1.21 \\
\hline 2 & 12.5 & -1.2 & -1.1 & 2.40 & 0.86 & 1.05 \\
\hline 3 & 14.8 & -2.6 & -2.4 & 2.21 & 1.15 & 0.94 \\
\hline 4 & 13.3 & -1.1 & -0.3 & 2.56 & 0.63 & 0.52 \\
\hline 5 & 13.9 & -1.4 & -1 & 2.13 & 0.59 & 0.46 \\
\hline 6 & 13.1 & -4.2 & -4.6 & 2.37 & 0.54 & 1.04 \\
\hline 7 & 6.6 & -1.9 & -2 & 4.64 & 0.62 & 0.89 \\
\hline 8 & 13.5 & -3.6 & -2.9 & 1.75 & 1.01 & 1.1 \\
\hline 9 & 9.2 & -0.8 & -0.8 & 4.93 & 0.73 & 0.7 \\
\hline 10 & 12.1 & -3.9 & -3.6 & 2.82 & 0.58 & 0.81 \\
\hline 11 & 16.8 & 1.1 & 1 & 5.47 & 0.52 & 0.67 \\
\hline 12 & 12.3 & -2.6 & -2.5 & 2.91 & 1.28 & 1.29 \\
\hline 13 & 7.2 & 1 & 1.2 & 3.84 & 0.77 & 1.02 \\
\hline 14 & 12.5 & -2.3 & -1.7 & 2.25 & 1.65 & 1.63 \\
\hline 15 & 13.6 & -4.4 & -3.8 & 1.78 & 1.33 & 1.4 \\
\hline
\end{tabular}

FU indicates follow up 

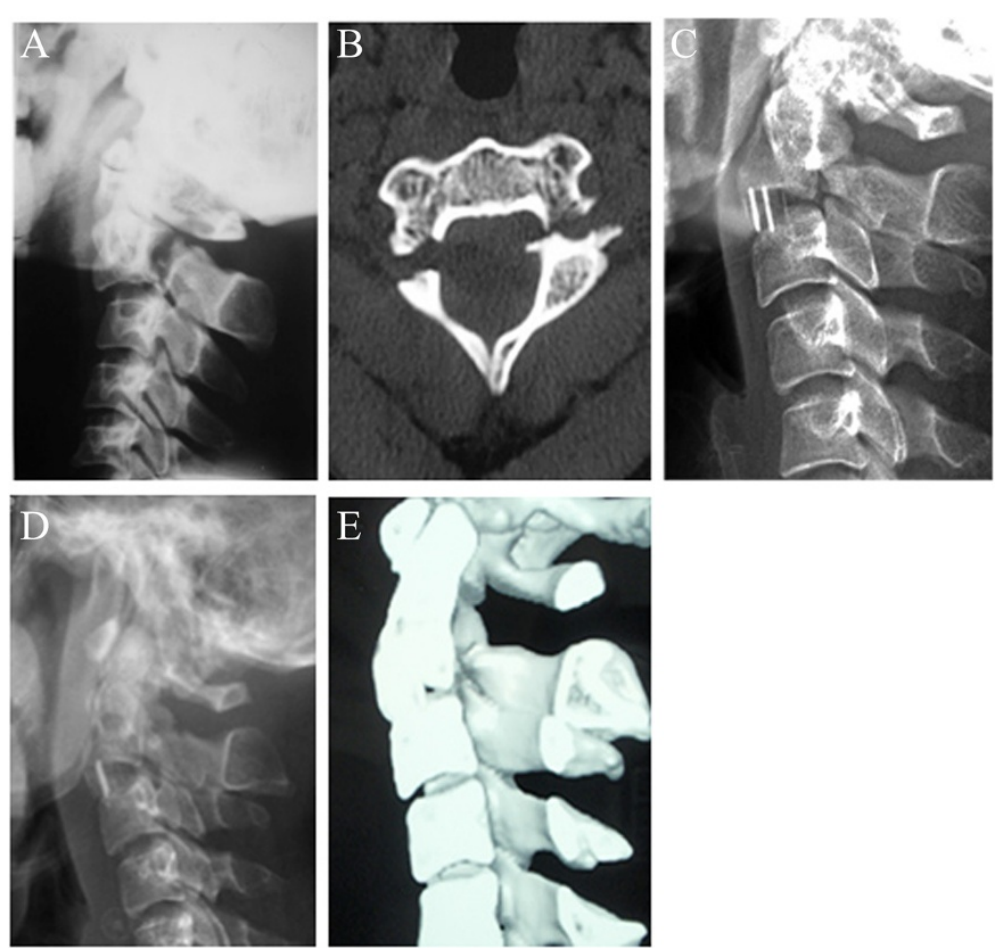

Fig. 4 Images of a 26-year-old female patient. a and $\mathbf{b}$, preoperative lateral X-ray and CT scans showing a type II hangman's fracture with severe translation. c, Postoperative lateral X-ray showing minor implant migration at 1 week postoperatively. $\mathbf{d}$, The X-ray showed the implant remained the same position during follow-up. e, Bone fusion was confirmed using CT scan at 4 months postoperatively

fixation and prevent migration/extrusion of the cage. Furthermore, the cage was made of PEEK material, a thermoplastic material with high molecular weight, whose elasticity modulus was similar to that of bone [33]. This helped to minimize stress shielding and subsidence of the cage and allowed optimum interaction of compressive forces at the graft-host interface, which could avoid significant subsidence and result in high fusion rate that our study has confirmed. We also performed biomechanical evaluation of this cage for type II Hangman's fracture, which showed that there were no significant difference in range of motion (ROM) of lateral bending, rotation and extension between the cage group and bone graft plus plating group, except ROM of flexion, which could be partly compensated by hard cervical collar [35]. However, it is imperative to emphasize that this surgical method can not be applied to all the Hangman's fracture cases.

The fact that one patient in this study manifested evident minor implant migration was also given close attention. In this case, the local kyphotic angle was more than $15^{\circ}$ combined with more than $5.0 \mathrm{~mm}$ translation of $\mathrm{C} 2$ preoperatively. Therefore, in our late clinical practice, candidates for this study were strictly limited to the patients with local kyphotic angle of $15^{\circ}$ or less and translation of $5.0 \mathrm{~mm}$ or less. Since then, in our follow up, we have not seen any case with implant migration yet. One important reminder is that we did not include type III fractures in our study due to low incidence. We suggest not to utilize this surgical method to treat type III Hangman's fracture due to severe instability.

The incidence of donor site morbidity has been reported to be as high as $20-30 \%$ in some series of ACDF, and deficits included acute and chronic pain, infection, and nerve injury $[29,30,36]$. Harvesting of structural corticocancellous autologous bone from the iliac crest may lead to excessive pain and morbidity at the donor site, as well as iliac crest fracture [37, 38]. In our series, because there was no need for a structural graft, cancellous bone was harvested via a much smaller opening than with earlier methods, reducing the incidence of morbidity. There were no complications related to the donor site in this study. Several authors have reported the placement of cages filled with bone substitute or even those that are empty; $[39,40]$ however, there is evidence, that the patient's own bone is associated with the best fusion rates $[41,42]$.

Following a Hangman's fracture, lots of patients suffer chronic neck pain sufficiently intense to affect daily life. Some authors ascribed the axial neck pain to the cervical disc injury or to the presence of a fracture on the inferior facet of the axis [43]. Another reason of residual neck pain may be local kyphosis at C2-3 [43], as well as 
the absence of fusion or pseudarthrosis after opration. In this study, no patient complained of suffering neck pain at the latest follow up. This could be contributed to $\mathrm{C} 2 /$ 3 discectomy and solid fusion. However, this needed to be verified by further study and the results of a longterm follow up.

The hospitalization period was relatively short (4-15 days with an average of 7.3 days) and the need for longer hospitalization was attributed to the patients with head trauma and fractures of extremities, who required the help of the nursing and physical therapy staff, allowing early mobility of the patients, their removal from the bed, and the reduction of the lesions.

The authors appreciated the limitations of any standalone device when compared with an anterior plate. Postoperative external immobilization is certainly necessary in the absence of a plate; however, the risk of device extrusion was probably less with this kind of cervical cage as a $\mathrm{s}$ result of titanium pins and retention teeth over the superior and inferior surfaces.

In our study, the anterior approach was especially appropriate for Hangman's fracture combined with intervertebral disc injury or disc herniation compressing the spinal cord. Using the anterior approach with this kind of cervical cage in management of these fractures, solid fusion was achieved in all cases without complications. In our experience, the anterior approach with the cervical cage stabilization without plating, which can shorten the duration of surgery and medical cost, may be an alternative for type II / IIA Hangman's fracture when properly indicated.

However, the current case series have some limitations. It was a small-sized prospective study and the number of patients was restricted due to the low incidence of Hangman's fracture. Another limitation is that this study was just a preliminary report about an early technical experience based on the results of 2-year's follow up. A multicenter prospective controlled study of Hangman's fracture should be considered in the future.

\section{Conclusions}

This study demonstrates that anterior $\mathrm{C} 2 / 3$ discectomy and interbody fusion with the cervical cage solely is effective and reliable in management of type II / IIA Hangman's fracture with $\mathrm{C} 2 / 3$ disc injury when properly indicated. One important reminder is that this method is not suitable for the treatment of all Hangman's fracture cases. Further studies are warranted to clarify its proper indication.

\section{Abbreviations}

ACDF: Anterior discectomy and interbody fusion; PEEK: Polyetherether ketone; VAS: Visual analog scale; PTNC: Post-traumatic neck score; ROM: Range of motion.

\section{Competing interests}

The authors declare that they have no competing interests.

\section{Authors' contributions}

F.W., L.W., and S.L. designed this protocol. F.W., S.L., L.W. and Z.Z. performed surgery for the patients. R.Z., and M.G. followed up these patients and performed clinical outcome evaluation. X.P. followed up these patients and performed radiological outcome evaluation. S.C. performed the statistical analysis. All authors read and approved the final manuscript.

\section{Authors' information}

Not applicable.

\section{Acknowledgements}

We thank Bo Jiang and Yingming Chen for technical assistance of radiological assessment.

\section{Funding}

This study was founded by National Natural Science Foundation of China (No. 81401839; No.U1032001), Natural Science Foundation of Guangdong (No. S2013010015775), National Basic Research Program of China (973 Program, No.2012CB619105) and China Postdoctoral Science Foundation (No. 2013 M531876).

\section{Author details}

'Department of Spine Surgery, The First Affiliated Hospital of Sun Yat-sen University, Guangzhou, China. ${ }^{2}$ The medical school of Shenzhen University, Shenzhen, Guangdong, China. ${ }^{3}$ Department of Radiology, The First Affiliated Hospital of Sun Yat-sen University, Guangzhou, China.

Received: 15 December 2014 Accepted: 24 September 2015 Published online: 06 October 2015

\section{References}

1. Cho DY, Liau WR, Lee WY, Liu JT, Chiu CL, Sheu PC. Preliminary experience using a polyetheretherketone (PEEK) cage in the treatment of cervical disc disease. Neurosurgery. 2002;51(6):1343-50.

2. Pryputniewicz DM, Hadley MN. Axis fractures. Neurosurgery. 2010;66(3 Suppl):68-82.

3. Vaccaro AR, Madigan L, Bauerle WB, Blescia A, Cotler JM. Early halo immobilization of displaced traumatic spondylolisthesis of the axis. Spine (Phila Pa 1976). 2002;27(20):2229-33.

4. Verheggen R, Jansen J. Hangman's fracture: arguments in favor of surgical therapy for type II and III according to Edwards and Levine. Surg Neurol. 1998;49(3):253-62.

5. Levine AM, Edwards CC. The management of traumatic spondylolisthesis of the axis. J Bone Joint Surg Am. 1985;67(2):217-26.

6. Tuite GF, Papadopoulos SM, Sonntag VK. Caspar plate fixation for the treatment of complex hangman's fractures. Neurosurgery. 1992;30(5):761-4.

7. Hur H, Lee JK, Jang JW, Kim TS, Kim SH. Is it feasible to treat unstable hangman's fracture via the primary standard anterior retropharyngeal approach? Eur Spine J. 2014;23(8):1641-7.

8. Tian W, Weng C, Liu B, Li Q, Hu L, Li ZY, et al. Posterior fixation and fusion of unstable Hangman's fracture by using intraoperative three-dimensional fluoroscopy-based navigation. Eur Spine J. 2012;21(5):863-71.

9. Li XF, Dai LY, Lu H, Chen XD. A systematic review of the management of hangman's fractures. Eur Spine J. 2006;15(3):257-69.

10. Ludwig SC, Kowalski JM, Edwards II CC, Heller JG. Cervical pedicle screws: comparative accuracy of two insertion technique. Spine (Phila Pa 1976). 2000;25(20):2675-81.

11. Ludwig SC, Kramer DL, Balderston RA, Vaccaro AR, Foley KF, Albert TJ, Placement of pedicle screws in the human cadaveric cervical spine: comparative accuracy of three techniques. Spine (Phila Pa 1976). 2000;25(13):1655-67.

12. Ludwig SC, Kramer DL, Vaccaro AR, Albert TJ. Transpedicle screw fixation of the cervical spine. Clin Orthop Relat Res. 1999:359:77-88.

13. Xu H, Zhao J, Yuan J, Wang C. Anterior discectomy and fusion with internal fixation for unstable hangman's fracture. Int Orthop. 2010;34(1):85-8.

14. El Masry WS, Tsubo M, Katoh S, El Miligui YH, Khan A. Validation of American Spinallnjury Association (ASIA) motor score and the national acute spinal cord injury study (NASCIS) motor score. Spine. 1996;21(5):614-9. 
15. McGrory BJ, Klassen RA. Arthrodesis of the cervical spine for fractures and dislocations in children and adolescents. A long-term follow-up study. J Bone Joint Surg Am. 1994;76(11):1606-16.

16. Shin JJ, Kim SH, Cho YE, Cheshier SH, Park J. Primary surgical management by reduction and fixation of unstable hangman's fractures with discoligamentous instability or combined fractures. J Neurosurg Spine. 2013;19(5):569-75.

17. Chen BL, Wei FX, Ueyama K, Xie DH, Sannohe A, Liu SY. Adjacent segment degeneration after single-segment PLIF: the risk factor for degeneration and its impact on clinical outcomes. Eur Spine J. 2011;20(11):1946-50.

18. Lin CN, Wu YC, Wang NP, Howng SL. Preliminary experience with anterior interbody titanium cage fusion for treatment of cervical disc disease. Kaohsiung J Med Sci. 2003;19(5):208-16.

19. Coric D, Wilson JA, Kelly Jr DL. Treatment of traumatic spondylolisthesis of the axis with nonrigid immobilization: a review of 64 cases. J Neurosurg. 1996;85(4):550-4.

20. Liu J, Li Y, Wu Y. One-stage posterior C2 and C3 pedicle screw fixation or combined anterior C2-C3 fusion for the treatment of unstable hangman's fracture. Exp Ther Med. 2013;5(3):667-72.

21. ElMiligui $Y$, Koptan W, Emran I. Transpedicular screw fixation for type II Hangman's fracture: a motion preserving procedure. Eur Spine J. 2010;19(8):1299-305.

22. Ma W, Xu R, Liu J, Sun S, Zhao L, Hu Y, et al. Posterior short-segment fixation and fusion in unstable Hangman's fractures. Spine (Phila Pa 1976). 2011;36(7):529-33.

23. Wilson AJ, Marshall RW, Ewart M. Transoral fusion with internal fixation in a displaced hangman's fracture. Spine (Phila Pa 1976). 1999;24(3):295-8.

24. Ying Z, Wen Y, Xinwei W, Yong T, Hongyu L, Zhu H, et al. Anterior cervical discectomy and fusion for unstable traumatic spondylolisthesis of the axis. Spine (Phila Pa 1976). 2008:33(3):255-8.

25. Rajasekaran S, Vidyadhara S, Shetty AP. Iso-C3D fluoroscopy-based navigation in direct pedicle screw fixation of Hangman fracture: a case report. J Spinal Disord Tech. 2007;20(8):616-9.

26. Samaha C, Lazennec JY, Laporte C, Saillant G. Hangman's fracture: the relationship between asymmetry and instability. J Bone Joint Surg Br. 2000;82(7):1046-52.

27. Yukawa Y, Kato F, Ito K, Horie Y, Hida T, Nakashima H, et al. Placement and complications of cervical pedicle screws in 144 cervical trauma patients using pedicle axis view techniques by fluoroscope. Eur Spine J. 2009:18(9):1293-9.

28. Suchomel P, Hradil J, Barsa P, Buchvald P, Lukás R, Taller S, et al. Surgical treatment of fracture of the ring of axis-"hangman's fracture". Acta Chir Orthop Traumatol Cech. 2006;73(5):321-8.

29. Riew KD, Rhee JM. The use of titanium mesh cages in the cervical spine. Clin Orthop Relat Res. 2002;394:47-54.

30. Hacker RJ. Threaded cages for degenerative cervical disease. Clin Orthop Relat Res. 2002;394:39-46.

31. Bose B. Anterior cervical fusion using Caspar plating: analysis of results and review of the literature. Surg Neurol. 1998;49(1):25-31.

32. Gaudinez RF, English GM, Gebhard JS, Brugman JL, Donaldson DH, Brown CW. Esophageal perforations after anterior cervical surgery. J Spinal Disord. 2000;13(1):77-84

33. Kulkarni AG, Hee HT, Wong HK. Solis cage (PEEK) for anterior cervical fusion: preliminary radiological results with emphasis on fusion and subsidence. Spine J. 2007;7(2):205-9.

34. Savolainen S, Rinne J, Hernesniemi J. A prospective randomized study of anterior single-level cervical disc operations with long-term follow-up: surgical fusion is unnecessary. Neurosurgery. 1998;43(1):51-5.

35. Huang YL, Liu SY, Zhao WD, Liang CX, Li HM, Wei FX. Biomechanical evaluation of Solis cervical cage for typellHangman's fracture. Chinese journal of Spine and Spinal Cord. 2009;19(4):285-9.

36. Buttermann GR. Prospective nonrandomized comparison of an allograft with bone morphogenic protein versus an iliac-crest autograft in anterior cervical discectomy and fusion. Spine J. 2008:8(3):426-35.

37. Hu RW, Bohlman HH. Fracture at the iliac bone graft harvest site after fusion of the spine. Clin Orthop. 1994:309:208-13.

38. Reale F, Gambacorta D, Mencattini G. Iliac crest fracture after removal of two bone plugs for anterior cervical fusion. Case report J Neurosurg. 1979;51(4):560-1

39. Payer M, May D, Reverdin A, Tessitore E. Implantation of an empty carbon fiber composite frame cage after single-level anterior cervical discectomy in the treatment of cervical disc herniation: preliminary results. J Neurosurg. 2003;98(2 Suppl):143-8

40. Agrillo U, Mastronardi L, Puzzilli F. Anterior cervical fusion with carbon fiber cage containing coralline hydroxyapatite: preliminary observations in 45 consecutive cases of soft-disc herniation. J Neurosurg. 2002;96(3 Suppl):273-6.

41. Martin Jr GJ, Haid Jr RW, MacMillan M, Rodts Jr GE, Berkman R. Anterior cervical discectomy with freeze-dried fibula allograft. Overview of 317 cases and literature review. Spine (Phila Pa 1976). 1999;24(9):852-8.

42. Sagi HC, Young ML, Gerstenfeld L, Einhorn TA, Tornetta P. Qualitative and quantitative differences between bone graft obtained from the medullary canal (with a Reamer/Irrigator/Aspirator) and the iliac crest of the same patient. J Bone Joint Surg Am. 2012;94(23):2128-35.

43. Watanabe M, Nomura T, Toh E, Sato M, Mochida J. Residual neck pain after traumatic spondylolisthesis of the axis. J Spinal Disord Tech. 2005;18(2):148-51.

\section{Submit your next manuscript to BioMed Central and take full advantage of:}

- Convenient online submission

- Thorough peer review

- No space constraints or color figure charges

- Immediate publication on acceptance

- Inclusion in PubMed, CAS, Scopus and Google Scholar

- Research which is freely available for redistribution 